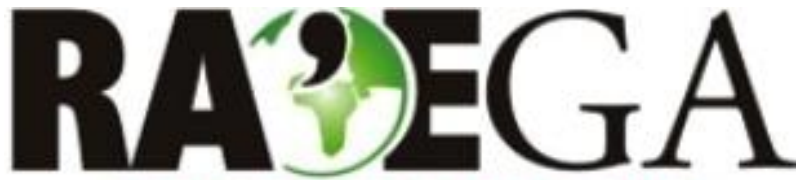

O ESPACCO GEOGRÁFICO EM ANÁLISE

\title{
RESENHA \\ AS DEZESSETE CONTRADIÇÕES E O FIM DO CAPITALISMO
}

Flávio Ribeiro de Lima $^{1}$

Recebido em: 06/03/2016

Aceito em: 29/11/2017

Grande esforço e brilhantismo teórico e reflexivo demarcam a obra do geógrafo David Harvey $^{2}$ cujos argumentos analíticos repousam, sobretudo, na teoria marxista. A obra 17 Contradições e o fim do capitalismo ${ }^{3}$ invoca os efeitos econômicos, políticos e sociais mediante as diversas crises que o sistema capitalista tem sofrido ao longo do tempo, buscando compreender suas limitações e ajudando-nos a pensar como superá-las.

A compreensão da lógica de superação das crises é o caminho percorrido por Harvey para empreender uma crítica ao modo como o sistema capitalista conforma a vida cotidiana, tendo em vista que, à medida que o sistema se revitaliza, aumentam-se os níveis de exploração: tanto a humana quanto a de recursos naturais. Da mesma forma, aumentam os níveis de subordinação que, por sua vez, funcionam como

\footnotetext{
${ }^{1}$ Universidade Federal do Paraná, UFPR, Curitiba/PR, e-mail: flavior_lima@hotmail.com

2 David Harvey é professor catedrático do Departamento de Antropologia da City University of New York Graduate School

3 Para a execução deste texto, debruçamo-nos sobre a obra original (em inglês) lançada no ano de 2014. Para melhor situar as reflexões do autor e indicar de modo coerente os termos aqui demonstrados, recorremos à versão da obra em espanhol, lançada em 2015 na Espanha e no Equador. Sendo assim, as traduções dos respectivos excertos aqui mencionados, bem como as indicações, foram realizadas pelo autor e poderão ser encontradas na versão original. Vale lembrar que, no momento em que estávamos a finalizar este texto, a editora brasileira Boitempo lançou a versão da obra em português.
}

motor desse sistema, levando-nos a adaptarmonos aos novos estágios de acumulação de capital e a vivermos como se estivéssemos amarrados ao sistema.

A grandeza da discussão recupera, de modo sucinto, discussões iniciadas por uma gama de autores ilustres (dentre os quais, destacamos Karl Marx, Henri Lefebvre, Karl Polanyi, Guy Debord, André Gorz e inúmeros outros), de modo a recupera-las aos dias atuais.

Emerge então o argumento de que as crises são manifestações internas do capital; por isso mesmo o autor objetiva analisar as 17 contradições que serão aqui apresentadas, de modo a formular respostas - contraditórias em certos momentos - aos problemas que temos enfrentado, demonstrando, sobretudo, qual poderia ser sua eventual realocação (HARVEY, 2014: p. 25).

Nota-se um delicioso movimento, que vai da totalidade do urbano ao plano do cotidiano da população, que elucida os caminhos teóricos e metodológicos percorridos nessa construção. Para tanto, observa-se que foi necessário desmistificar as contradições existentes no âmago da sociedade, por meio de tensões entre a realidade e a aparência, desvendando o que sucede verdadeiramente por trás das múltiplas capas de aparências superficiais muitas vezes enganosas em nossas vidas. Esse percurso implica a compreensão do conceito marxista de fetichismo que, em larga medida, representa as diversas máscaras, disfarces e distorções do que 


\section{RESENHA - "AS DEZESSETE CONTRADIÇÕES E O FIM DO CAPITALISMO"}

sucede realmente no mundo que nos rodeia (p.20).

A obra está dividida em três momentos de discussão, propostos como: contradições fundamentais (os primeiros sete capítulos); a segunda parte, nomeada como as contradições dinâmicas (do oitavo ao 14을 capítulo); e a terceira parte, em que se discorre sobre as contradições perigosas (do capítulo 15으 ao 17으). Vale lembrar que os três momentos não se separam, mas sim se entrelaçam, prendendo a atenção do leitor desde o início até o fim.

Uma das características admiráveis em Harvey é a dimensão do horizonte geográfico mundial apresentado por meio dos ricos e oportunos exemplos das diversas cotidianidades expostas.

Ao apresentar as primeiras contradições, as fundamentais, Harvey lembra que essas são constantes e que possuem papel dominante no sistema capitalista: sem elas, o capital sequer poderia sustentar-se.

O autor apresenta a primeira contradição, valor de uso e valor de troca, com magnificência, lembrando, inicialmente, que os valores de uso são infinitamente variados e que os de troca são qualitativamente idênticos. Para exemplificar a primeira contradição, ele traz o exemplo do valor de uso e de troca de uma moradia. Nesse caso, o valor de uso aplica-se quando se realiza um financiamento a fim de adquirir uma moradia com o intuito de habitar. Já o valor de troca traz consigo uma série de signos (interesses, ganância, especulação) e condicionantes (localização, materiais utilizados em sua construção, tamanho do terreno e outros) que o determinam (p. 58). Essas diferenças convertem a moradia (e não apenas nesse exemplo, mas na educação, na saúde etc.) num artigo ressignificado, num objeto de especulação. Isso porque ela agrega não apenas o preço do habitar e sim uma série de outros elementos (acima especificados) necessários à reprodução do capital que, por sua vez, desencadeia bolhas especulativas no mercado imobiliário.

Na segunda contradição, o valor social do trabalho e sua representação em dinheiro,
Harvey demonstra como o dinheiro oferece ao sistema capitalista a possibilidade de medir o valor de diferentes mercadorias, do qual a força de trabalho, que é por ele obscurecida, serve-nos de expressivo exemplo. Isso em razão de o dinheiro representar o valor social de todas as atividades, de todos os trabalhos, sendo o intermédio pelo qual os proprietários dos meios de produção podem reivindicar o trabalho social que será aplicado pelo operário.

O dinheiro permite, em primeira ordem, a passagem da relação simbólica que possui para uma relação de poder. No entendimento do autor, o dinheiro falsifica as formas de representação do trabalho social; mais que isso, cria um conjunto de máscaras (fetiche) que oculta a socialização do trabalho (p. 46). É exatamente essa disparidade que representa a segunda contradição.

A propriedade privada e o Estado capitalista (terceira contradição) são trazidos ao debate de forma sucinta nas simulações desenvolvidas pelo autor. Isso porque o direito à propriedade privada confere a possibilidade de vender (trocar) o que é de posse. Porém, a imposição desses direitos depende da existência dos poderes estatais, de um sistema jurídico e de um sistema legal que codifique e defina as obrigações contratuais que correspondem ao direito de propriedade privada e ao direito dos indivíduos jurídicos individuais. Embora sejam antagônicos, Estado e capital andam juntos, realizam-se por meio de acordos comercias e alianças (p. 58). No entendimento de Harvey, é exatamente o uso desse poder que se legitima por meio de imposição da violência contra os grupos desfavorecidos na grande maioria dos casos, visando à proteção e centralização de riquezas, que torna a propriedade privada, um regime de direitos repleto de contradições.

$\mathrm{Na}$ apresentação da quarta contradição, Apropriação privada e riqueza comum, Harvey se debruça na compreensão dos modos de mercantilização e monetarização de tudo que existe sobre a terra nos dias de hoje. Isso porque trabalho (atividade essencial), terra (natureza convertida em propriedade privada) e dinheiro 


\section{RESENHA - “AS DEZESSETE CONTRADIÇÕES E O FIM DO CAPITALISMO”}

(representação mascarada) - fundamentais para a reprodução de capital - nunca desapareceram e sim criaram formas legais e ilegais que legitimam a despossessão. O paradoxo é, na verdade, o fato de essas formas de despossessão serem administradas sob o disfarce virtuoso da política de austeridade supostamente requerida para devolver ao capitalismo doente uma situação aparentemente saudável (p. 69). Todas essas práticas formam um nó coletivo em que a política de acumulação por despossessão se converte em meio primordial para a extração de renda e de riqueza das populações vulneráveis, incluindo a classe trabalhadora (p.78).

Reunindo informações significativas, Harvey apresenta a quinta contradição entre capital e trabalho. Ela se deve ao fato de a mercantilização da força de trabalho ser a única forma de salvar uma contradição aparentemente insolúvel da circulação de capital. Isso porque a força de trabalho é uma mercadoria que tem capacidade mutável e através dela, os trabalhadores, em resumo, criam mais valor do que recebem.

O trabalhador dispõe dessa força de trabalho e a vende a quem lhe convém, de modo supostamente "livre" (p. 73), e isso é o que significa para ele a liberdade frente ao domínio do capital. Aos olhos de Harvey, ao realizar essa venda, o trabalhador está diretamente atrelado às formas contemporâneas de dominação que, por sua vez, ocorrem para além da esfera fabril, estendendo-se para a vida cotidiana. Assim se processa porque o trabalhador vende sua força de trabalho como forma de sobrevivência e, para os detentores dos meios de produção, a compra significa a continuidade na geração de riqueza. Sendo assim, os trabalhadores se veem em condições de dominação, e a liberdade, em seu sentido mais amplo, atrela-se à escravidão ( $p$. 261).

Na sexta contradição capítulo, O capital é uma coisa ou um processo? David Harvey ocupase na construção dos argumentos que sustentem sua afirmação diante dessa dualidade. Assim procede porque em determinado momento o capital assume outras formas (a do dinheiro, por exemplo), a fim de dar continuidade em sua acumulação. Ao se produzir uma mercadoria, por exemplo, temos capital empregado e, neste momento da produção (que têm-se apresentado cada vez mais acelerada em razão das inovações tecnológicas e da intensificação da exploração da força de trabalho), o capital se apresenta como uma coisa (objeto). No momento da venda, quando a mercadoria estará de fato realizada, o capital reassume a forma dinheiro. $E$ todo esse movimento faz com que o capital persista na dualidade entre coisa e, ao mesmo tempo, processo. Definitivamente, o capital é um processo social, mas é igualmente capaz de materializar-se em coisas.

Em A unidade contraditória entre produção e realização (sétima contradição), o autor busca apresentar de modo conciso essas duas unidades. A contínua circulação de capital depende de êxito em dois momentos: o primeiro é o momento em que se empreende produção de mercadorias (através da exploração da força de trabalho) e o segundo é o momento que a mercadoria é consumida (através do consumo advindo do dinheiro que foi trocado por sua força de trabalho), isto é, realizada.

A contradição situa-se entre a produção e a realização que pode, sem dúvidas, mitigar-se de diversas formas. Para começar, pode incrementar a demanda frente à caída dos salários mediante a expansão da magnitude total da mão de obra. A unidade contraditória entre produção e realização aplica-se, então, tanto ao destino vital dos trabalhadores como ao capital (p. 94). Logo, na proposta de Harvey, o capital não apresentase estável, nem permanente, senão em contínua mudança de suas características (p. 110).

De um parágrafo a outro, Harvey dá a nós, seus leitores, a sensação de estarmos presos num sufocante sonho em que, mesmo estando-se a um passo de acordar, avançamos à inerte covardia que nos destrói sem precedentes. Sua pesquisa continua a reafirmar a contribuição através da densidade de dados e das contextualizações que são apresentadas na seção contradições dinâmicas. 


\section{RESENHA - “AS DEZESSETE CONTRADIÇÕES E O FIM DO CAPITALISMO”}

A oitava contradição, Tecnologia, trabalho e disponibilidade humana, enfoca o espetacular aumento de produtividade alcançado pelo capital que, por sua vez, constitui um paradoxo que pode explodir em forma de crise. Tomando as inovações tecnológicas como ponto de partida, Harvey demonstra como o uso dos recursos naturais, que satisfazem as necessidades do sistema capitalista por meio da exploração e do controle da força de trabalho, serve para elevar o aumento da produção e assim a rentabilidade de capital (p. 103). Esse movimento de automatização faz com que haja menos postos de trabalho, tocando na aparente estrutura de empregos no âmago da sociedade e, no entendimento de Harvey, culmina em crescentes taxas de exploração tanto do trabalho quanto dos recursos naturais.

As Divisões do trabalho (nona contradição) é outro tema para o qual o autor chama atenção. Segundo ele, refere-se à capacidade humana de decompor atividades - produtivas e reprodutivas - complexas em tarefas especificamente simples, que podem ser realizadas por distintos indivíduos (p.119).

O capital se apoia em mudanças organizacionais e tecnológicas para reduzir os salários, alentando a capacitação massiva em habilidades especializadas, objetivando a especialização, o aumento da produtividade, a competição entre os trabalhadores, a segmentação dos postos de trabalho, apoiados pela arquitetura e pela disciplina. Isso é "pensar os trabalhadores como 'mãos', preferindo esquecer que os mesmos também possuem estômago e cérebro" (p. 131); torná-los meros operadores de máquinas e assim mantê-los alienados.

A décima contradição, Monopólio e concorrência: centralização e descentralização, traz o tema da concorrência. O autor estrutura seus argumentos em três pontos. O primeiro ponto "consiste em centralizar o capital em megacorporações e assim estabelecer alianças mais flexíveis, que dominem os mercados" ( $p$. 142). No segundo ponto, asseguram-se ainda mais firmemente os direitos de monopólio da propriedade privada mediante as leis comerciais internacionais que regulam todo o comércio global (proteção de patentes e acordos sobre licenças). No terceiro e último ponto, o argumento opera mediante as marcas comerciais que permitem aplicar um preço de monopólio a uns sapatos com um emblema determinado ou a um vinho com o nome de certo Château na etiqueta. A partir desses argumentos, tem-se que o capital se move em vários níveis centralizando poder e inovações e descentralizando o que não é útil para sua reprodução.

$\mathrm{Na} 11^{\text {ạ }}$ contradição, Desenvolvimentos geográficos desiguais e produção do espaço, o geógrafo se detém em compreender o papel do capital e do Estado na paisagem geográfica. No entendimento de Harvey, o capital se esforça em produzir espaços favoráveis à sua reprodução e, consequentemente, à sua evolução, afetando diretamente o espaço de diversas regiões do globo terrestre (p. 149 e 150). Para tanto, a inovação tecnológica, que contribui na diminuição do tempo de produção e na invenção de meios de transportes viáveis para o deslocamento das mercadorias, e os benefícios cedidos pelo Estado (diminuição nos custos de instalação e de impostos) possuem fundamental importância.

Desse modo, o capital cria uma paisagem geográfica que satisfaz suas necessidades em lugares e em momentos determinados, só para ter que destruí-la em um momento posterior a fim de facilitar sua nova expansão e transformação 'qualitativa'. Assim o capital desencadeia os poderes da destruição criativa sobre a terra, moldando o espaço e o tempo segundo suas necessidades (p. 157). Em Harvey "sem o desenvolvimento geográfico desigual e suas contradições, há muito tempo o capital já estaria ossificado e se tornado caótico" (149).

A visão das disparidades de renda e riqueza, 12a contradição, reúne várias exposições que levam Harvey a questionar a absurda desigualdade que apresenta o sistema capitalista.

Ao capital interessa, de imediato, manter tão baixo quanto seja possível os níveis salariais para que haja maiores taxas de lucro. Como já foi 


\section{RESENHA - “AS DEZESSETE CONTRADIÇÕES E O FIM DO CAPITALISMO”}

visto, essa tática define uma contradição intrínseca entre realização e produção. Mais que isso, permite aos ricos gestar os meios de comunicação, isto é, continuar a alienar a classe trabalhadora via aparato do Estado (impostos e políticas monetárias).

Obedecendo aos padrões de acumulações distintos, o sistema leva a classe dos ricos (detentores dos meios de produção) a tornaremse cada vez mais ricos; e as classes desfavorecidas (trabalhadores) a se tornarem cada vez mais pobres e a assumirem os custos da reprodução social, já que o capital socializa as perdas e privatiza o lucro. Em suma, a disparidade na distribuição de renda é fundamental à sustentação do sistema capitalista uma vez que igualdade de distribuição e reprodução de capital, nesse sistema, são coisas incompatíveis (p. 172).

Umas das características que Harvey mais admira no capitalismo é o modo como se apropria, a todo o momento, da vida cotidiana, reinventando-se; mais que isso, reproduzindo-se a ponto de dar origem a tantas contradições.

O autor mergulha, adiante, empilhando argumentos e dispondo de exposições concretas que o ajudam a memorar a Reprodução social (13a contradição). Para assegurar a reprodução social, o capital humano necessita especializar-se e, ainda assim, não produz com a destreza de um maquinário. Em condições normais de realização da atividade laboral (normas e temporalidades previstas na Organização Internacional do Trabalho - OIT) o trabalhador (capital humano) não consegue ser altamente produtivo ao ponto de gerar mais-valia suficiente para que o capital siga em sua abundante acumulação, nem mesmo com altos níveis de especialização educacional. 0 ponto de vista de Harvey, que é o mesmo de Marx, assevera que o trabalhador só pode produzir mais-valia em condições de exploração, isso porque a reprodução social absorve uma grande quantidade de trabalho não pago (p. 188).

Os trabalhadores assumem importância no âmbito da produção de mais-valia e também ao receber seus salários (que se apresentam cada vez menores) já que, ao recebê-los, devem decidir onde e como gastá-los (consumo), e isso interessa diretamente ao capital. Esse movimento, exploratório e mercantil, penetra e altera o ritmo da vida cotidiana para além da esfera fabril e demonstra que reprodução social não se pode entender fora dessas circunstâncias geograficamente diferenciadas.

$\mathrm{Na}$ 14a a contradição, Liberdade e dominação, pode-se presenciar um conjunto de argumentos relacionados ao que se entende em âmbito geral por liberdade. A maioria de nós, socializados no sistema capitalista, acreditamos estar dotado de uma capacidade de liberdade de pensamento, independente dos muros e das barreiras que nos rodeiam (p. 197). O autor desconstrói essa narrativa de senso comum argumentando que os teóricos que consideram lógico esse entendimento, reproduzem grande equívoco. Ao criticar esse pensamento, o autor expõe: para haver reprodução de capital, a liberdade e a dominação têm de caminhar juntas, tem de situarem-se "nos extremos de uma contradição que adota muitas formas sutis e matizadas por não dizer disfarçadas" (p. 201). Sendo assim, os trabalhadores são livres num duplo sentido. Livre para vender sua força de trabalho aos capitalistas e livres (despossuídos nos termos de Harvey) do controle sobre os meios de produção. É exatamente nesse modo de submissão que situa-se este paradoxo, já que a liberdade que conhecemos associa-se ao privilégio e camufla as formas de escravaturas ( $p$. 203 e 203).

Escoltado na ânsia de constituir argumentos que conectem a enorme gama de paradoxos que o sistema capitalista apresenta em sua fase atual, o autor retrata, de forma única, as três últimas contradições. As contradições perigosas são grandes riscos para o presente imediato, não apenas para a capacidade do motor econômico do capitalismo continuar a funcionar, como também para a reprodução da vida humana em condições minimamente razoáveis.

A primeira das contradições perigosas (15 contradição), abarca o Crescimento exponencial infinito e sua insuficiência diante do modelo 


\section{RESENHA - "AS DEZESSETE CONTRADIÇÕES E O FIM DO CAPITALISMO"}

econômico que se tem apresentando ao longo dos últimos anos. Como foi exposto nas contradições anteriores, o capital segue na busca infinita de obter mais benefícios, ora explorando de modo desavergonhado a classe trabalhadora, ora se apropriando de formas de reprodução antes não apropriadas. Ou, ainda, utilizando-se de artifícios midiáticos, constituindo uma sociedade pautada no espetáculo e no consumo. A grande questão é que o lucro exacerbado também pode tornar-se um grande problema para o capital, afinal, "onde vai parar todo este dinheiro excedente?” (p. 228).

Desde sua aparição, até os dias de hoje, o capital tem encontrado saídas, como empréstimos aos bancos, aos Estados ou ainda dívidas contraídas por hipoteca. No entendimento do autor, essa perpétua acumulação do capital em um ritmo exponencial mediante a criação exponencial de dinheiro pode descarrilhar a relação econômica que move o motor do capital. E, como se sabe, a economia do crescimento zero resultante seria a sentença da morte do capitalismo. Isso porque, sem essas formas de "expansão não haveria capital" (p.228). Em suma, "é como se estivéssemos no quadrado número vinte e um do tabuleiro de xadrez e não pudéssemos seguir" (p. 225).

Todavia, esse modelo se apresenta insustentável quando o tema é a Relação do capital com a natureza (16ạ contradição). Ao seguir nessa acumulação infinita, o capital necessita acumular todos os elementos encontrados no meio ambiente, privatizando-os, mercantilizando-os, sem levar em conta: as relações com os recursos naturais, com a capacidade de absorver substâncias contaminantes ou de lidar com a degradação dos habitats, a perda de biodiversidade, o risco ambiental, a contaminação da qualidade do ar, da terra e da água ou, ainda, o esgotamento e/ou alteração da natureza (p. 241).

$O$ desenho que se apresenta na atualidade, mostra-se insuficiente e caminha com vistas ao esgotamento das fronteiras de expansão do capital, agudizando a degradação cancerosa da natureza para adquirir novas possibilidades de acumulação. Nesse ínterim, fazse necessário observar a crítica de Harvey à postura que se tem diante dos desastres naturais: aos seus olhos, trata-se de uma contradição interna e não externa ao capital (p. 253), que aliena a sociedade ao ponto de aceitar o modelo de ecossistemas artificiais e tecnocráticos funcionais ao capital.

Seguindo a apresentação das contradições que nutrem o que poderia ser, no entendimento de Harvey, o declínio do sistema capitalista, o autor apresenta o último capítulo, A revolta da natureza humana: alienação universal (última contradição). No movimento criado pelo autor, a alienação (da terra, da mente e do corpo) é apontada como um elemento crucial. Os fetichismos e ficções, que infiltraram a vida cotidiana e tornaram-na sublimada, sistematizada e alienada, introduziram também necessidades supérfluas, "pervertidas em prol da circulação do capital” (p. 268).

A qualquer momento, os grupos excluídos (coletivo de trabalhadores) podem afrontar coletivamente as múltiplas formas de alienação e rebater o insustentável modelo do sistema capitalista, tal qual se apresenta. Seria uma forma de combater as desigualdades sociais e as disparidades econômicas, de pôr fim à exploração desmedida do meio ambiente, encontrando por exemplo, alternativas para a perpetuação da acumulação do dinheiro.

Após a apresentação dos dezessete presseitos, Harvey aponta o que nomeou de perspectivas de um futuro feliz e disputado: a promessa do humanismo revolucionário, considerações em que expõe, com a mesma coerência textual e dialética apresentada ao longo de toda a obra, questionamentos ao leitor para um mundo melhor que este que temos herdado. $O$ autor indica possibilidades de reivindicar e reinventar os direitos no plano do espaço, para assim gozarmos da plenitude de uma vida realizada.

Nessa perspectiva, todos os capítulos jorram em nós gotas de pensamentos que transbordam em nossas mentes e nos fazem refletir sobre nosso compromisso como 
pesquisadores e agentes sociais diante de um futuro repleto nuvens carregadas de incertezas que nos amedrontam e assombram.

Na obra, Harvey questiona o pensamento colonial que se instaurou na sociedade preconizando a nós, pesquisadores, ao mesmo tempo agentes sociais, a tarefa de desconstruir ou "curar as mentes das almas danificadas" (p. 280). Para tanto, critica o pensamento humanista que evidencia determinadas categorias de análise (sobretudo a do indivíduo), demonstrando que, a ciência humana se faz da totalidade, desde o plano cotidiano até se chegar aos elementos complexos que compõem a sociedade.

Como em Karl Marx, a esperança de Harvey é que o conjunto de trabalhadores perceba o perigo que os ameaça muito antes que a pobreza chegue ainda mais longe (momento que $\mathrm{o}$ dano aos seres humanos e ao meio ambiente já será grande demais para ser recuperado). É necessário, portanto, que a Bela Adormecida desperte a tempo, para que possamos assistir a um final parecido com os dos contos de fadas (p. 283).

O excerto abaixo, retirado do último capítulo da obra, finaliza magistralmente a abordagem marxista de David Harvey e toda a construção a qual fizemos essa breve apresentação: $O$ capitalismo nunca vai cair por si próprio. Terá de ser empurrado. "A acumulação de capital nunca vai cessar. Terá de ser interrompida. A classe capitalista nunca vai entregar voluntariamente seu poder. Terá de ser despossuída" (p. 258), compreender isso, foi e segue sendo (nos termos de Karl Marx) fundamental.

\section{REFERÊNCIAS}

HARVEY, David. Seventeen contradictions and the end of capitalism. Londres: Editora Profile Books, 2014.

HARVEY, David. Diecisiete contradicciones y el fin del capitalismo. Barcelona: Iaen, 2015. 